\title{
A TEORIA GERAL DA GINÁSTICA, O TRABALHO PEDAGÓGICO, A FORMAÇÃO DOS PROFESSORES E AS POLÍTICAS PÚBLICAS NO CAMPO DA GINÁSTICA: CONTRIBUIÇÕES DA PESQUISA MATRICIAL DO GRUPO LEPEL/FACED/UFBA
}

\author{
Roseane Soares Almeida, Universidade Federal da Bahia - UFBA, Bahia, Brasil \\ Celi Nelza ZülkeTaffarel, Universidade Federal da Bahia - UFBA, Bahia, Brasil \\ Micheli Ortega Escobar, Universidade Federal de Pernambuco - UFPE, Pernambuco, Brasil \\ Cristina Souza Paraiso, Universidade Federal da Bahia - UFBA, Bahia,Brasil \\ Amália Catharina Santos Cruz, Universidade Estadual de Feira de Santana, Brasil \\ Alexandre Francisco Lordello, Universidade Federal da Bahia - UFBA, Bahia,Brasil \\ Ana Rita Lorenzini, Universidade de Pernambuco, Pernanbuco - UPE, Brasil \\ Roseane Cruz Freire Rodrigues, Universidade Federal da Bahia - UFBA, Bahia,Brasil \\ Quênia Rebouças dos Santos, Universidade Federal da Bahia - UFBA, Bahia,Brasil \\ Fábio Rigaud, Universidade Federal da Bahia - UFBA, Bahia,Brasil
}

\section{RESUMO}

O presente estudo localiza-se no Grupo LEPEL - Estudo e Pesquisa em Educação Física, Esporte e Lazer. Está sendo desenvolvido no eixo curricular conteúdos específicos, do Curso de Licenciatura em Educação Física da UFBA e envolve estudantes da graduação e da pósgraduação. Trata do conhecimento da Ginástica, seus sentidos e significados na construção da Teoria Pedagógica, tendo como objetivo elaborar a teoria como categorias da prática, considerando as problemáticas referentes à produção do conhecimento, à formação de professores, à prática pedagógica, à política pública e às proposições superadoras. Utiliza procedimentos investigativos próprios à pesquisa matricial e problematiza o conhecimento da Ginástica. $\mathrm{O}$ estudo caracteriza-se como pesquisa qualitativa com dados empíricos coletados em diferentes fontes. Articula-se com a formação continuada de professores e trata da organização do trabalho pedagógico da escola. A hipótese do trabalho investigativo é que existem possibilidades concretas de tratar o conhecimento, levando em consideração os ciclos do pensamento, a partir de categorias da prática. Dados da realidade apontam, a partir das contradições do movimento de inclusão/exclusão, possibilidades de construção de uma nova cultura do trato da Ginástica no contexto da formação e da escola básica.

Palavras-Chaves: Teoria geral da ginástica; Trabalho pedagógico; Formação de professor.

\section{A GENERAL THEORY OF GYMNASTICS, EDUCATIONAL WORK, TRAINING FOR TEACHERS AND PUBLIC POLITICAL IN THE FIELD OF GYMNASTICS: CONTRIBUTIONS MATRIX RESEARCH GROUP LEPEL / FACED / UFBA}

\footnotetext{
ABSTRACT

This study is located in LEPEL Group - Study and Research in Physical Education, Sport and leisure. It is being developed in the axis-specific curricular content, the Bachelor of Physical Conexões: revista da Faculdade de Educação Física da UNICAMP, Campinas, v. 10, n. Especial, p. 98-114, dez. 2012.98 ISSN: 1983-9030
} 
Education UFBA and involves students of undergraduate and postgraduate. This knowledge of Gymnastics, their meanings in the construction of Pedagogical Theory, aiming to develop the theory and practice of categories, considering the problems relating to the production of knowledge, training of teachers, the pedagogical practice, public policy and superadoras propositions. Uses investigative procedures own research matrix and discusses the knowledge of Gymnastics. The study is characterized as qualitative research with empirical data collected from different sources. Articulates with the continuing education of teachers and addresses the organization of educational work of the school. The hypothesis of the research work is that there are real possibilities of treating knowledge, taking into account the cycles of thought, from categories of practice. Data reality show, from the contradictions of the movement of inclusion / exclusion, possibilities of building a new culture of Gymnastics tract in the context of training and basic school.

Key-Words: General theory of gymnastics; Pedagogical work, Teacher training.

\title{
LA TEORIA GENERAL DE GIMNASIA, EL TRABAJO PARA LA EDUCACIÓN, LA FORMACIÓN DE PROFESORES Y POLÍTICAS PÚBLICAS EN EL ÁMBITO DE LA GIMNASIA: CONTRIBUCIONES DE LA INVESTIGACIÓN MATRIZ DEL GRUPO LEPEL/ FACED / UFBA
}

\begin{abstract}
RESUMEN
Este estudio se encuentra en el Grupo LEPEL - Estudio y Investigación en Educación Física, Deportes y Recreación. Está siendo desarrollado en el contenido curricular específico del eje, la Licenciatura en Física y Educación de UFBA involucra a los estudiantes de pregrado y postgrado. Este conocimiento de la Gimnasia, su significado en la construcción de teoría pedagógica, con el objetivo de desarrollar la teoría y la práctica de las categorías, teniendo en cuenta los problemas relacionados con la producción de conocimientos, la formación de los docentes, la práctica pedagógica, política pública y propuestas superadoras.Utiliza los procedimientos de investigación matriz propia investigación y se analiza el conocimiento de Gimnasia. El estudio se caracteriza como la investigación cualitativa con los datos empíricos recogidos de diferentes fuentes. Se articula con la formación continua de los profesores y se dirige a la organización del trabajo educativo de la escuela. La hipótesis de la investigación es que hay posibilidades reales de tratamiento de conocimiento, teniendo en cuenta los ciclos de pensamiento, de las categorías de la práctica. Mostrar datos de la realidad, de las contradicciones del movimiento de las posibilidades de inclusión / exclusión, de la construcción de una nueva cultura del tracto Gimnasia en el contexto de la formación y de la escuela básica.
\end{abstract}

Palabras-Clave: Teoría general de la gimnasia; Trabajo pedagógico; Formación del profesorado. 


\section{INTRODUÇÃO}

O presente estudo aborda o desenvolvimento de uma Pesquisa Matricial. Está baseado na problematização da Ginástica enquanto campo de conhecimento, inserido no âmbito da Cultura Corporal, e tem como objetivo contribuir na construção da Teoria da Ginástica, por meio da crítica ao conhecimento produzido, crítica à prática nas aulas de Educação Física, às políticas públicas e a busca de proposições superadoras para organizar o conhecimento tomando por referência ciclos de desenvolvimento do pensamento, na escola pública e na formação de professores. Algumas questões balizam nossos estudos, a saber: Qual é o conhecimento reconhecido como Ginástica? Qual é sua gênese? Como se desenvolveu e que sentidos e significados assumiu nos diferentes modos de produção? Onde pode ser localizado no atual contexto histórico? Quais as suas bases, fundamentos científicos, técnicos e pedagógicos? Quais as classificações, modalidades e campos de trabalho da Ginástica? Como tratar esse conhecimento na formação de professores? Quais as proposições superadoras realidade e possibilidade - para organizar o conhecimento da ginástica nos ciclos de ensino da escola básica e no currículo de formação de professores?

\section{CONTRIBUIÇÕES DA PESQUISA MATRICIAL AOS ESTUDOS DA GINÁSTICA}

A base teórica que consubstancia o estudo é constituída pela concepção materialista dialética de história. Compreendemos que os sentidos e significados de todas as atividades são historicamente determinados, em última instância, pela base material da existência humana. A Ginástica é, portanto, uma construção humana, socialmente produzida, historicamente acumulada, que adquiriu sentidos e significados nas relações sociais contraditórias. Constituise em um saber e em conhecimento científico, cujo objeto são as exercitações corporais, e seu acesso deve ser garantido a todos.

A produção do conhecimento se dá na "apropriação do mundo" por meio da ação, da atividade real ${ }^{1}$, objetiva, material, existindo diferentes modos de apropriação, com diferentes intencionalidades que lhes são próprias, integradas por um sentido subjetivo e por um sentido

\footnotetext{
${ }^{1}$ Silvana Vilodre Goellner, ${ }^{1}$ em texto, discute a atividade e suas implicações no desenvolvimento humano, tendo em vista a ação na educação e educação física, a partir das contribuições de Vygotsky, Luria e Leontiev.

Conexões: revista da Faculdade de Educação Física da UNICAMP, Campinas, v. 10, n. Especial, p. 98-114, dez. 2012.100 ISSN: 1983-9030
} 
objetivo $^{2}$. Cada modo de apropriação, enquanto atividade baseada na práxis objetiva da humanidade, de caráter totalizador, está ligado a outras formas de apropriação, em maior ou menor medida.

Como modos de apropriação, podemos reconhecer do senso comum ao pensamento teórico ${ }^{3}$. O conhecimento teórico produzido nas relações sociais capitalistas adquire força produtiva, ideológica e política, ${ }^{4}$ à medida que altera relações e processos produtivos, serve a interesses de classes e, subsidia direções que devem assumir políticas públicas. Portanto, no currículo, no trato com o conhecimento, na dinâmica curricular, articulam-se: ${ }^{5}$

a) Os aspectos lógicos e históricos - características do objeto cognoscível -, referentes aos conceitos científicos e a relação entre disciplinas escolares e a ciência ou saber de referência, gerados e produzidos para além da escola;

b) Os aspectos psicológicos - características do sujeito cognoscente, cuja mente forma-se socialmente, cujas possibilidades de aprendizagens são também históricas; ${ }^{6-9}$

c) Os aspectos sociais, antropológicos e históricos - interesses e necessidades dos sujeitos, das classes, da sociedade, que se expressam, também, no interior da escola, não de maneira pacífica e harmônica, mas sim, por contradições, confrontos e conflitos ${ }^{4}$.

Cabe a Educação Física, enquanto disciplina científica, enquanto disciplina curricular, enquanto área de formação e intervenção profissional, contribuir com o debate refletindo sobre o currículo e suas possibilidades enquanto espaços de intervenção e conhecimento na

\footnotetext{
${ }^{2}$ Segundo Cheptulin, ${ }^{2}$ o desenvolvimento do conhecimento exige reconhecermos as categorias, seus conteúdos históricos e suas leis. O materialismo dialético estuda as formas gerais do ser, os aspectos e laços gerais da realidade, as leis do reflexo desta última na consciência dos homens. As formas essenciais da interpretação filosófica, do reflexo das propriedades e das conexões universais da realidade e das leis do funcionamento e do desenvolvimento do conhecimento são as categorias e as leis da dialética. Como elementos necessários da teoria filosófica, elas tem uma função ideológica - sistema de concepção do mundo, sistema total de ideias sobre a realidade, elabora atitude em relação a vida social, ao regime social, a compreender a essência da política adotada pelo estado, para participar de forma consciente da vida política - gnosiológica - sua assimilação permite um desenvolvimento da faculdade cognitiva, da capacidade de pensar com exatidão, cientificamente - e, metodológica - permitem formulação dos imperativos aos quais deve-se submeter a atividade de pensamento e a atividade prática, imperativos que constituem o método dialético, que elevam o nível do pensamento alargando possibilidades criativas. ${ }^{3}$ Segundo Chaui, ${ }^{3}$ a Ciência Antiga definia teoria como o estudo da realidade que independe de toda a ação e intervenção humana. A Ciência moderna afirmava que a teoria tinha como finalidade abrir caminho para que os homens se tornassem senhores da realidade natural e social, acreditando que a realidade existia em si mesma, separada do sujeito do conhecimento e que este poderia apenas descrevê-la por meio de leis e agir sobre ela por meio de técnicas. A Ciência contemporânea, não contempla nem descreve realidades, mas a constrói intelectual e experimentalmente.

${ }^{4}$ As discussões atuais sobre Projeto Político Pedagógico deixam isto bem evidente. Ver mais em Veiga. ${ }^{10}$

Conexões: revista da Faculdade de Educação Física da UNICAMP, Campinas, v. 10, n. Especial, p. 98-114, dez. 2012.101 ISSN: 1983-9030
} 
cultura pedagógica da escola e, para além dela, enquanto elemento da construção de uma dada hegemonia, frente às necessidades históricas de formação humana para a transformação da sociedade.

Essa necessidade traz em si uma exigência histórica para a formação humana. Esta exigência radica numa compreensão do homem como ser ativo e criativo, prático, que se transforma na medida em que transforma o mundo, pela sua ação material e social. Une-se aí a compreensão teórica à ação real, com vista à transformação radical da sociedade.

Estruturar um programa de Ginástica no currículo de formação profissional e selecionar os seus conteúdos é um problema metodológico básico, vez que quando se aponta o conhecimento e os métodos para sua assimilação, se evidencia a natureza do pensamento teórico que se pretende desenvolver.

Podemos dizer, assim, que o Programa é o pilar da disciplina e que seus elementos principais são: O conhecimento de que trata a disciplina, sistematizado e hierarquizado, o que geralmente se denomina de conteúdos de ensino; O tempo pedagogicamente necessário para o processo de assimilação do conhecimento; Os procedimentos didático-metodológicos para ensiná-lo e avaliá-lo de acordo com objetivos definidos. ${ }^{11}$

Considerando que o conhecimento de que trata a Educação Física é o conhecimento da Cultura Corporal, o estudo deste conhecimento visa apreender sua gênese e as necessidades estabelecidas historicamente, ampliando as possibilidades de compreensão, explicação e intervenção dos sujeitos na realidade contraditória e complexa.

Se a finalidade é, portanto, não só entender, pensar o mundo, mas transformá-lo, isto exige que a produção do conhecimento tenha como base a realidade que se quer transformar e o projeto histórico que se quer construir. ${ }^{12}$ É neste marco referencial que conceituamos a Educação Física e seu objeto de estudo: a Cultura Corporal. E reconhecemos a Ginástica, juntamente com a Dança, os Jogos, o Esporte e outras manifestações culturais, como um dos elementos constitutivos da Cultura Corporal.

Conexões: revista da Faculdade de Educação Física da UNICAMP, Campinas, v. 10, n. Especial, p. 98-114, dez. 2012.102 ISSN: 1983-9030 
Para o desenvolvimento e aprofundamento dos estudos, vimos construindo banco de dados a partir das seguintes fontes: livros, periódicos, dissertações, teses, anais de congressos, páginas na internet, documentos e, como bases de dados empíricos, as observações das práticas pedagógicas na escola e demais campos de atuação do professor de Educação Física. Para as questões do estudo utilizamos por procedimentos investigativos: Análise do conteúdo da literatura por meio de técnicas de fichamento em forma de esquemas e sínteses pessoais, elaboração de resumos analíticos das obras e trabalhos científicos selecionados; Análise de conteúdo dos diários de campo e registros em fotos e filmes das práticas na escola, bem como, análise do conteúdo das entrevistas com professores e alunos; Pesquisa diagnóstica e de implementação de experiências superadoras no trato com o conhecimento nos campos de trabalho, em especial a escola e a formação de professores.

As experiências constituem fonte privilegiada dos dados e vêm sendo desenvolvidas, sistematizadas e veiculadas através de ações nos campos da formação do professor e da escola básica, a partir de projetos de ensino, pesquisa e extensão. Ao longo dos anos vimos desenvolvendo o Projeto de Ginástica, orientado pela Pesquisa Matricial do Grupo da Linha de Estudos e Pesquisas em Educação Física, Esporte e Lazer-LEPEL/FACED/UFBA, privilegiando sua sistematização por dentro do currículo de formação de professores; das disciplinas do trato Ginástico; de Seminários Interativos; de Cursos no âmbito da Formação inicial e continuada; de Festivais de Cultura Corporal, junto a professores e alunos do curso de formação de professor de Educação Física e da escola básica.

As análises dos dados de estudos e experiências vêm sendo sistematizadas a partir do esforço do trabalho coletivo, com docentes e discentes da graduação e da pós-graduação, acerca do trato do conhecimento Ginástico e das suas possibilidades explicativas e práticas culturais. Tanto na formação de professores quanto na escola básica o conhecimento produzido vem sendo sistematizado em projetos de iniciação científica e de extensão de alunos da graduação; em monografias, dissertações e teses de alunos da Pós-Graduação; em Projetos de Pesquisa Docente $^{5}$, bem como, em outras atividades educativas previstas no currículo de formação dos

\footnotetext{
${ }^{5}$ PARAISO, Cristina S. Ginástica escolar e a materialização de propostas pedagógicas (Doutoranda); LORENZINI, Ana Rita. Conteúdo e método da educação física escolar no trato com a ginástica: contribuições da metodologia crítico superadora para construção da teoria pedagógica (doutoranda); LORDELLO, Alexandre Francisco. Organização do trabalho pedagógico no trato com o conhecimento do parkour/cultura corporal no Brasil: produção do conhecimento e possibilidades para uma Conexões: revista da Faculdade de Educação Física da UNICAMP, Campinas, v. 10, n. Especial, p. 98-114, dez. 2012.103 ISSN: 1983-9030
} 
professores.

No atual contexto o conjunto de estudos busca contribuir para o desenvolvimento teórico da Ginástica e para o desenvolvimento curricular do Curso de Licenciatura em Educação Física, de caráter ampliado, da UFBA e toma como objeto a cultura corporal, como eixo articulador do conhecimento a prática social (práxis) e como matriz científica a história. Os conhecimentos são tratados por sistemas de Complexos Temáticos ${ }^{6}$, relacionando-os aos Conhecimentos de Formação Ampliada, aos Conhecimentos Identificador da Área e ao Conhecimento Identificador do Aprofundamento de Estudos. Delimita os Conhecimentos de Formação Ampliada como aqueles que permitem uma compreensão de conjunto, radical e de totalidade, comum a qualquer tipo de formação profissional. Compreendem os estudos acerca das relações do ser humano com a natureza, com os demais seres humanos na sociedade, com o trabalho e com a educação, guiados pelos critérios: orientação científica; integração teoriaprática; relações do ser humano, do mundo do trabalho, da cultura corporal.

\section{A GINÁSTICA NO CURRÍCULO DE FORMAÇÃO DE PROFESSORES}

A Ginástica sempre se fez presente nos currículos de Educação Física \& Esporte através dos Métodos Ginásticos que visavam à preparação física, no âmbito das instituições formadoras ${ }^{7}$ e das escolas de ensino de nível básico.

A Educação Física esteve contemplada na primeira Lei de Diretrizes e Bases da Educação Nacional (Lei 4.024 de dezembro de 1961). Os motivos justificadores “[...] centravam-se no processo de industrialização do modelo econômico brasileiro, em substituição ao agrário de índole comercial-exportadora implementado nos anos 30 [...]", ${ }^{14: 05}$ e dessa forma apoiava-se na necessidade da capacitação física do trabalhador ao lado daquela de natureza técnica. Em diferentes tempos a Ginástica encontrava-se, e ainda encontra-se, marcada e marcando

\footnotetext{
formação humana (mestrando); RODRIGUES, Roseane Cruz Freire. A formação humana no ensino superior: a contribuição da pedagogia crítico-superadora (mestranda). SANTOS, Quênia Rebouças dos. Ginástica, dança: manifestações culturais de comunidades soteropolitanas (bolsista PIBIEX); RIGAUD, Fábio. Estudos sobre o trato das atividades circenses no âmbito da Educação física: a realidade e as possibilidades (candidato ao PIBIC); ALMEIDA, Roseane S. O conhecimento da ginástica no currículo de formação do professor de educação física da UFBA 2011 a 2014 (Pesquisadora Docente).TAFFAREL, Celi N. Z. Pequisa Matricial da Rede Lepel (Pesquisadora CNPQ).

${ }^{6}$ Adotamos a compreensão de Complexo Temático desenvolvida na obra de Pistrak. ${ }^{13}$

${ }^{7}$ A primeira escola de formação de professores de Educação Física foi criada somente em 1939, pelo Decreto-lei n. 1212, de 17 de abril de 1939, até então os profissionais que atuavam nas escolas eram os instrutores formados pelas instituições militares. $^{11: 53}$

Conexões: revista da Faculdade de Educação Física da UNICAMP, Campinas, v. 10, n. Especial, p. 98-114, dez. 2012.104 ISSN: 1983-9030
} 
interesses e prioridades da classe hegemônica ${ }^{8}$.

Observa-se na realidade educacional brasileira, que o seu ensino, na maioria das vezes, não segue orientação específica de uma pedagogia emergente, de vertentes teóricas contemporâneas progressistas, ou diretrizes curriculares claramente definidas, em uma perspectiva que aponte caminhos para a superação. No currículo escolar tradicional brasileiro, podemos encontrar manifestações da Ginástica de várias linhas europeias, que se caracterizam pelas formas básicas do Atletismo como caminhar, correr, saltar e arremessar, bem como, formas básicas da Ginástica como pular, empurrar, levantar, carregar; além dos exercícios em aparelhos, onde citamos o balançar na barra fixa, equilibrar na trave olímpica, exercícios com aparelhos manuais (salto com arcos, cordas) e diferentes formas de luta.

Dieckert ${ }^{15: 11-12}$ na condição de professor visitante (Santa Maria/RS) trouxe uma relevante contribuição à área, tecendo críticas acerca da forma como a Educação Física apresentava-se nas escolas. Dizia ele: “O Brasil precisa de um novo tipo de Educação Física. O Objetivo central não pode ser a produção e comprovação de rendimento, mas a motivação dos alunos para uma prática para toda a vida”.

Ainda hoje, constatamos nos programas de ensino da escola básica (ensino fundamental e médio), a influência da Calistenia e da esportivização ${ }^{9}$, marcando o desenvolvimento do conteúdo da Ginástica, sobressaindo em sua prática a tendência à "esportivização", "elitização" e até mesmo o "sexismo", reforçando arbitrariamente padrões femininos e masculinos de movimento. Ainda sobre os aspectos esportivos, identificamos que os conhecimentos da Ginástica são tratados como apêndice dos esportes, limitando-se a servir de aquecimento no início das aulas, ou como relaxamento após o seu término. ${ }^{16}$

Recorrendo aos estudos de Dieckert ${ }^{15: 11}$ para tecer a crítica à esportivização mencionada: "O

\footnotetext{
${ }^{8}$ Os livros de autores como: Carmen Lúcia Soares, intitulados: Educação Física: Raízes Européias e Brasil e Imagens da Educação no corpo; José Luíz dos Anjos, Corporeidade, Higienismo e Linguagem, Temáticas e discursos da corporeidade; Amarílio Ferreira Neto, em Pesquisa histórica na Educação Física brasileira; entre outros, trazem estudos históricos que revelam os verdadeiros interesses estabelecidos pela classe dominante às práticas corporais em diferentes momentos históricos no cenário mundial e também, presentes no processo de escolarização brasileiro, especificamente, no campo da Ginástica. Por isso, não pretendemos nos aprofundar sobre essa questão, visto que na literatura nacional ela se faz presente de forma contundente e bem elaborada.

${ }^{9}$ Manifestações ginásticas que com o tempo foram evoluindo e tornando-se atividades esportivas, submetendo-se às regras oficiais e movimentos padronizados. Exemplo a Ginástica Artística ou Olímpica; Ginástica Rítmica Desportiva, entre outras...

Conexões: revista da Faculdade de Educação Física da UNICAMP, Campinas, v. 10, n. Especial, p. 98-114, dez. 2012.105 ISSN: 1983-9030
} 
Brasil precisa entender que o caminho para o esporte de alto rendimento é uma trilha estreita que só poderá ser disputado por alguns poucos selecionados. A Escola não se presta para isto".

O culto exacerbado ao corpo, mercado em ascensão, somado a volta frenética da concepção que relaciona estritamente atividade física e saúde, a reflexão a partir das bases do pensamento crítico do conteúdo da Ginástica na formação profissional se faz extremamente necessária. A Ginástica enquanto conteúdo curricular dos cursos de formação está presente desde a primeira Escola Superior Educação Física do Brasil, possuindo como característica, desde aquela época, tendência à esportivização e aos aspectos técnicos enquanto modalidade. Estudos de mestrado de Pereira, ${ }^{17}$ Bonetti ${ }^{18}$ e Barbosa ${ }^{19}$ corroboram no sentido de identificar as principais características dos conteúdos e tendências pedagógicas presentes no trato desse conhecimento nos cursos de formação em Educação Física \& Esporte.

Segundo Pereira, ${ }^{17}$ os professores de Ginástica das Instituições de Ensino Superior do Estado do Paraná, em sua maioria, balizam o desenvolvimento de suas ações pedagógicas na concepção de corpo dualista, com formação centrada em aprender um conjunto de atividades para poder ensinar, centrando-se no conhecimento das ciências biológicas e com grande valorização das atividades práticas e procedimentos técnicos, sem levar em conta a necessária base teórica.

Bonneti, ${ }^{18}$ ao investigar os programas de Ginástica I e II das Instituições de Ensino Superior do Estado de Santa Catarina, conclui que estes demonstram como concepções filosóficas e tendências pedagógicas uma visão biologicista de homem, tendo como principais objetivos a manutenção da saúde corporal e a aquisição da aptidão física, seguindo princípios pedagógicos de correntes do tecnicismo. Assim, não apresentam uma orientação pedagógica ao ensino formal, e, ainda menos, com uma pedagogia transformadora, de concepção educacional crítica.

Os estudos de Barbosa ${ }^{19}$ realizados nas Instituições de Ensino Superior (IES) do Paraná, também reforçam que a dimensão técnica e o conhecimento proveniente da área biológica 
estão presentes como fator predominante nos programas das disciplinas relacionadas às manifestações gímnicas, impedindo uma formação que dê condições aos futuros profissionais de perceberem as constantes significações e ressignificações desse conhecimento.

Esses dados nos permitem dizer que a formação profissional em Educação Física \& Esporte, em especial da Ginástica, não sofreu alterações significativas desde a primeira escola de Educação Física para cá.

Ao investigar os currículos de formação dos professores, Almeida ${ }^{20}$ identifica o conhecimento da Ginástica tratado de forma fragmentada e alienado, onde a técnica subsume o caráter social e político da atividade social. No currículo de formação do professor de Educação Física ${ }^{10}$ ainda predomina a Ginástica na sua forma esportivizada: Ginástica Rítmica Desportiva, terapêutica, Ginástica Postural, Ginástica especial, Ginástica escolar e uma disciplina Ginástica para o trato de seu histórico e fundamentos. Todas estas expressões são tratadas na formação como disciplinas estanques, que não se articulam entre si, fragmentadas em particularidades que impedem a sua compreensão como totalidade, como conhecimento articulado com as dimensões que a originaram: pedagógicas, científicas, lúdicas, artísticas, agonísticos, esportivas, entre outras. Constatamos também que nos currículos de formação de professores a base teórica da ciência do treinamento, que por sua vez está alicerçada nas ciências biológicas, é predominante para o trato dos seus fundamentos. As proposições metodológicas e os processos avaliativos têm como base o desenvolvimento das aptidões físicas e as competências técnicas. Constatamos que o currículo de formação do professor conserva a característica instrumental dos primeiros cursos de formação de professores, conforme demonstram estudos de Taffarel ${ }^{21-22}$ e Cesário ${ }^{23}$.

A Educação Física, utilizando-se do conhecimento das diferentes formas ou manifestações Ginásticas - Ginástica Artística, Ginástica Rítmica, Ginástica Aeróbica, etc., - tem procurado, “através da educação, adaptar o homem à sociedade, alienando-o da sua condição de sujeito histórico, capaz de interferir na transformação" da sociedade, na perspectiva de contribuir para criação de melhores condições de vida. ${ }^{11: 36}$

\footnotetext{
${ }^{10} \mathrm{O}$ dados referem-se a análise do currículo da UFBA no período de 2001 a 2005, ano do desenvolvimento da pesquisa de campo.

Conexões: revista da Faculdade de Educação Física da UNICAMP, Campinas, v. 10, n. Especial, p. 98-114, dez. 2012.107 ISSN: 1983-9030
} 
Reconhecemos que, ao se estabelecer os conhecimentos tratados e veiculados nos programas de ensino nas instituições educacionais através de seus currículos, definem-se os pressupostos teóricos que trazem consigo a visão de mundo e de sociedade que se pretende construir, formar e implementar. Definem-se as relações de poder e hegemonia de uma sociedade. Na visão de Silva: ${ }^{24: 15}$

o currículo é sempre o resultado de uma seleção [...], (que) deduzem o tipo de conhecimento que é considerado importante justamente a partir de descrições sobre o tipo de pessoa que elas consideram ideal. [...] Afinal, um currículo busca precisamente modificar as pessoas que vão 'seguir' aquele currículo.

Assim, tomando como base os estudos da teoria crítica ${ }^{11}$ da educação, o conhecimento estabelecido para o currículo, representa e carrega consigo as marcas das relações sociais de poder, reproduzindo culturalmente as estruturas existentes em nossa sociedade. Portanto, nossos interesses buscam responder questões como: Quais os conhecimentos que estão sendo produzidos no campo da Ginástica? O que essas produções priorizam enquanto interesses de investigações? Qual a característica dessas produções ligadas ao conhecimento da Ginástica? Afinal, de que Ginástica estamos falando?

Ao entender que as produções científicas podem e devem penetrar o universo de nossas discussões, influenciando os conteúdos tratados no interior de nossas salas de aulas, é necessário identificar o que está sendo apontado, hoje, como objeto de discussão entre os profissionais da área de Educação Física \& Esporte, especificamente, no âmbito da Ginástica.

\section{A GINÁSTICA NO CURRÍCULO DA ESCOLA BÁSICA}

De acordo com a proposição inerente à obra do Coletivo de Autores ${ }^{11}$ e ratificada nos estudos de Almeida, ${ }^{20}$ partimos da constatação de que o conhecimento da Ginástica faz parte do acervo da cultura corporal e, consequentemente, faz parte da atividade produtiva e criativa fundamental da vida humana, o trabalho. Compreendemos que, a partir do desenvolvimento das forças produtivas das relações sociais, a cultura corporal humana foi sendo determinada e

\footnotetext{
${ }^{11}$ O movimento de explosão da literatura crítica ocorreu nos anos setenta e oitenta. A teoria crítica do currículo estabelece novas formas de conceber e entender os propósitos e problemas educacionais. Caracterizou-se por uma reação a concepção tradicional de currículo isolado, parcial, dotado de racionalidade técnica e desarticulado do contexto sócio-político e cultural. Conexões: revista da Faculdade de Educação Física da UNICAMP, Campinas, v. 10, n. Especial, p. 98-114, dez. 2012.108 ISSN: 1983-9030
} 
construída e, as atuais formas e conteúdos da Ginástica, fruto desse desenvolvimento.

No percurso histórico da Ginástica identificamos que a sua presença no campo da escola foi consequência de uma série de determinações e condições históricas e sociais, que hoje precisam ser resgatadas e compreendidas para aprofundarmos nossas análises e definir proposições, que possam contribuir para seu desenvolvimento no atual contexto sociocultural.

Investigações desenvolvidas pelo Grupo LEPEL/FACED/UFBA, através de observações em uma amostra de escolas públicas da rede estadual de ensino do Estado da Bahia ${ }^{12}$, no em torno da UFBA, e da análise de programas e currículos, permitiram constatar que o conhecimento da Ginástica está sendo negado às crianças e jovens na escola pública.

Segundo dados disponíveis nos estudos $\mathrm{SUDEB}^{25}$ esta situação é predominante na maior parte do sistema estadual de ensino. A Rede Pública Estadual da Bahia é constituída por 1.943 unidades escolares. Destas 721 possuem quadras. Destas 672 são descobertas e somente 49 são cobertas. 1.222 escolas não possuem quadras. Ao todo são 2.333 professores da disciplina Educação Física. Destes 1.223 com formação específica na área. 12 com formação em outras áreas e 1.098 sem formação acadêmica. Frente a estes dados temos nos perguntado pelas determinações sociais e pedagógicas que explicam o fato do conhecimento da Ginástica está sendo excluído da escola no atual contexto?

A Ginástica enquanto campo de conhecimento, formação profissional e prática cultural não ficou incólume ao processo pelo qual o ser humano não reconhece, do ponto de vista social, econômico e psicológico, o fruto do seu trabalho. Uma Ginástica agonizante na escola, mas, exaltada nos meios de comunicação de massa, é o indicativo da contradição em que vivemos, que transforma a cultura de um povo em algo para ser consumido e assistido e não para ser construído, criticado, transformado. Pode-se definir a prática pedagógica da ginástica no

\footnotetext{
${ }^{12}$ As escolas que compõe o em torno da UFBA e com as quais o Curso de Educação Física busca interação para desenvolver projetos na área da Ginástica são as seguintes: Colégio Estadual Senhor do Bonfim - Barris; Núcleo Educacional Góes Calmon - Barris; Colégio Úrsula Catharino - Politeama; Colégio Estadual Ipiranga - 2 de Julho; Colégio Estadual Deputado Manoel Novaes - Araújo Pinho; Ginásio Servidor Público - Carlos Gomes; Centro Educacional Edgar Santos - Garcia; Escola Hildete Lomanto - Garcia; Colégio Estadual Odorico Tavares - Vitória; Escola de $1^{\circ}$ Grau João das Botas - Barra; Escola de $1^{\circ}$ Grau Wilson Lins - Ondina; Centro de Educação Especial da Bahia - Ondina; Instituto Pestalozzi da Bahia Ondina; Colégio Estadual Evaristo da Veiga - Garibaldi; Escola Henriqueta Martins Catarino - Federação; Escola de $1^{\circ}$ Grau Mário Costa Neto - Federação.

Conexões: revista da Faculdade de Educação Física da UNICAMP, Campinas, v. 10, n. Especial, p. 98-114, dez. 2012.109 ISSN: 1983-9030
} 
contexto escolar como predominantemente aferrada a princípios, motivos e esquemas do pensamento positivista, idealista e cientificista, que afastam-na das condições concretas e objetivas da realidade social, destituindo suas práticas das necessidades sociais e interesses pessoais, próprias da atividade humana. Tal contexto constitui uma problemática que exige investigação científica a partir de uma ampliação da visão social e histórica, que nos leve a reconhecer as contradições e, a partir dessas, identificar e construir novas possibilidades objetivas e concretas para o enfrentamento do trato Ginástico.

Os dados, até então sistematizados, nos permitem afirmar que são múltiplas as determinações que condicionam a ginástica na escola. No entanto, a determinação última é o trabalho pedagógico. Supomos que é na organização do trabalho e sua divisão social que se expressa a contradição das relações capitalistas, relações estas que penetram no interior da escola e da sala de aula para determinar o trato com o conhecimento. O conhecimento da ginástica não fica fora das relações gerais de produção. Da primitiva ginástica presente na cultura grega, como elemento relevante para a formação do cidadão, à ginástica dos anos oitocentos, recuperada pela necessidade de disciplinar a força de trabalho, ao estágio atual do desaparecimento da ginástica na escola, identificamos um elemento comum: as necessidades do mundo do trabalho.

A organização da força de trabalho no setor da economia política corresponde às formas de organização do trabalho pedagógico na formação de professores e na prática pedagógica da escola. Portanto, é necessário tomar como pressuposto o "Trabalho", atividade humana que, objetivada pela necessidade, constrói e produz as condições objetivas e subjetivas da formação do ser social e das suas atividades.

\section{CONSIDERAÇÕES FINAIS}

O presente texto expôs síntese dos estudos que vêm sendo realizados acerca da Ginástica na formação de professores e na escola básica, tendo por referência a Pesquisa Matricial do Grupo LEPEL/FACED/UFBA, que parte do reconhecendo das problemáticas ginásticas construídas ao longo do desenvolvimento da humanidade, conferindo-as diferentes sentidos e significados. Nessa perspectiva, continuamos levantando questões norteadoras dos estudos para identificarmos como o conteúdo da Ginástica vem sendo tratado; quais os seus impactos 
na formação do professor de educação física e quais as consequências desta na intervenção profissional.

Utilizando a história como matriz científica para apreensão do movimento dinâmico da realidade complexa e contraditória, assim como, o método materialista histórico dialético como aquele que orienta a nossa visão de mundo, auxiliando-nos a traçar estratégias para a compreensão mais aprofundada das relações e nexos no contexto da sociedade capitalista. Nossos estudos constatam que a Ginástica na formação e na escola ainda não supera as bases explicativas dos métodos positivistas, com sérias limitações explicativas acerca das problemáticas na área da saúde/aptidão física, limitando-se ao treino corporal. Tais fatos demonstram os limites para compreendê-la dentro da complexidade social e histórica com que este conhecimento foi se desenvolvendo pela humanidade, a partir de necessidades vitais, sendo criado e recriado em diferentes gerações e contextos, agregando conhecimentos de outras áreas e, por conseguinte, apontando os limites explicativos até então hegemônicos. Diante dos dados podemos afirmar que a forma como a Ginástica vem sendo tratada nos currículos de formação de professores precariza e aliena o trato desse conhecimento, inviabilizando desenvolvê-lo e ampliá-lo nas suas diferentes dimensões e possibilidades e, consequentemente, refletindo-se no trabalho pedagógico da escola.

Por fim, entendemos a necessidade de dar consequências aos estudos atualmente em desenvolvimento para aprofundarmos a compreensão do atual estágio de desenvolvimento da cultura corporal, em suas várias matizes, em especial as políticas públicas para a Ginástica. Reconhecermos a partir de suas contradições as possibilidades superadoras, pautadas por critérios científicos, pela integração teoria-prática, pelas relações do ser humano no mundo do trabalho e na sua cultura corporal.

\section{REFERÊNCIAS}

${ }^{1}$ GOELLNER, S. V. A categoria da atividade e suas implicações no desenvolvimento humano. Revista Brasileira de Ciências do Esporte, v. 13, n. 2, p. 288-292, jan., 1992.

${ }^{2}$ CHEPTULIN. A Dialética materialista: categorias e leis da dialética. São Paulo: AlfaOmega, 1982.

Conexões: revista da Faculdade de Educação Física da UNICAMP, Campinas, v. 10, n. Especial, p. 98-114, dez. 2012.111 ISSN: 1983-9030 
${ }^{3}$ CHAUI, M. Ética e universidade. In: REUNIAL ANUAL DA SOCIEDADE BRASILEIRA PARA O PROGRESSO DA CIENCIA, 46., Vitória, 1994. Anais... Vitoria, 1994.

${ }^{4}$ KATZ, C.; BRAGA, R.; COGGIOLA, O. Novas tecnologias: crítica da atual reestruturação produtiva. São Paulo: Xamã, 1995

5 SAVIANI, N. Saber escolar, currículo e didática: problemas da unidade/método no processo pedagógico. Campinas: Autores Associados, 1998.

${ }^{6}$ MOLL, L. Vygotsky e a educação: implicações pedagógicas da psicologia sócio-histórica. Porto Alegre: Artes médicas, 1996.

${ }^{7}$ VYGOTSKY, L. Pensamento e linguagem. São Paulo: Martins Fontes. 1986.

${ }^{8}$ VYGOTSKY, L. Formação social da mente. São Paulo: Martins Fontes, 1984.

${ }^{9}$ VYGOTSKY, L. LURIA, A . LEONTIEV, A . Linguagem, desenvolvimento e conhecimento. São Paulo: Ícone/EDUSO, 1988.

${ }^{10}$ VEIGA, I. P. Projeto político pedagógico da escola: uma construção possível. Campinas: Papirus, 1995.

${ }^{11}$ SOARES, C. L. et al. Metodologia do ensino da Educação Física. São Paulo: Cortez, 1992.

${ }^{12}$ KUENZER, A. Desafios teórico-metodológicos da relação trabalho-educação e o papel social da escola. In: FRIGOTTO, G. Educação e crise do trabalho: perspectivas de final de século. Petrópolis: Vozes, 1998.

${ }^{13}$ PISTRAK. M. M. Fundamentos da escola do trabalho. São Paulo: Expressão Popular, 2000.

Conexões: revista da Faculdade de Educação Física da UNICAMP, Campinas, v. 10, n. Especial, p. 98-114, dez. 2012.112 ISSN: 1983-9030 
${ }^{14}$ CAStellani filho, L. Política educacional e Educação Física. Campinas: Autores Associados, 1998.

${ }^{15}$ DIECKERT, J. Elementos e princípios da Educação Física. Rio de Janeiro: Ao livro técnico, 1985.

${ }^{16}$ NEGRINE, A.; GAUER, R. Educação Física e desporto, uma visão pedagógica e antropológica. Porto Alegre: Posenato, 1990.

${ }^{17}$ PEREIRA, A. M. Concepção de corpo: a realidade dos professores de Ginástica das Instituições de Ensino Superior do Estado do Paraná. 1998. 138 f. Dissertação (Mestrado em Educação)-Universidade Metodista de Piracicaba, Piracicaba, 1998.

${ }^{18}$ BONETTI, A. Ginástica: em busca de sua identificação no âmbito escolar. 1999. 101 f. Dissertação (Mestrado em Educação Física)-Centro de Desportos, Universidade Federal de Santa Catarina, Florianópolis, 1999.

${ }^{19}$ BARBOSA, I. P. A ginástica nos cursos de licenciatura em Educação Física do Estado do Paraná. 1999. 100 f. Dissertação (Mestrado em Educação Física)-Faculdade de Educação Física, Universidade Estadual de Campinas, Campinas, 1999.

${ }^{20}$ ALMEIDA, R. S. A ginástica na escola e na formação de professores. 2005. 157 f. Tese (Doutorado em Educação)-Faculdade de Educação, Universidade Federal da Bahia, Salvador, 2005.

${ }^{21}$ TAFFAREL, C. N. Z. A formação do educador: o processo de trabalho pedagógico e o trato com o conhecimento no curso de Educação Física. 1993. 302 f. Tese (Doutorado em Educação)-Faculdade de Educação, Universidade Estadual de Campinas, Campinas, 1993.

${ }^{22}$ TAFFAREL, C. et al. Projeto de ensino e pesquisa: o conhecimento da ginástica, a formação dos professores, a política pública, a prática pedagógica e as proposições superadoras na escola pública. Salvador: BA, 2001. Grupo LEPEL/FACED/UFBA [mimeo.] 
${ }^{23}$ CESÁRIO, M. A organização do conhecimento da ginástica no currículo de formação inicial do profissional de educação física: realidade e possibilidades. $219 \mathrm{f}$. Dissertação (Mestrado em Educação)-Faculdade de Educação, Universidade Federal de Pernambuco, 2001.

${ }^{24}$ SILVA, T. T. Documentos de identidade: uma introdução às teorias do currículo. Belo Horizonte: Autêntica, 1999.

${ }^{25}$ SUDEB. SUPERINTENDÊNCIA DE DESENVOLVIMENTO DA EDUCAÇÃO BÁSICA. A Educação Física e a ginástica nas unidades escolares públicas estaduais. Salvador: Coordenação de Educação Física e Esporte Escolar: Neuber Leite Costa, 2005. 